\title{
Fine-Needle Aspiration Molecular Analysis for the Diagnosis of Papillary Thyroid Carcinoma Through BRAFV600E Mutation and RET/PTC Rearrangement
}

\begin{abstract}
Giuseppe Pizzolanti, ${ }^{1}$ Leonardo Russo, ${ }^{1}$ Pierina Richiusa, ${ }^{1}$ Vincenzo Bronte, ${ }^{1}$ Rosa Bianca Nuara, ${ }^{2}$ Vito Rodolico, ${ }^{2}$ Marco C. Amato, ${ }^{1}$ Lucia Smeraldi, ${ }^{1}$ Pasqua S. Sisto, ${ }^{1}$ Miriam Nucera, ${ }_{1}^{1}$ Alessandra Bommarito, ${ }^{1}$ Roberto Citarrella, ${ }^{1}$ Renato Lo Coco, ${ }^{3}$ Daniela Cabibi, ${ }^{2}$ Alessio Lo Coco, ${ }^{1}$ Francesco Frasca, ${ }^{4}$ Gaspare Gulotta, ${ }^{5}$ Mario A. Latteri, ${ }^{6}$ Giuseppe Modica, ${ }^{7}$ Aldo Galluzzo, ${ }^{1}$ and Carla Giordano ${ }^{1}$
\end{abstract}

Objective: To evaluate $\mathrm{BRAF}^{\mathrm{V} 600 \mathrm{E}}$ mutation on consecutive fine-needle aspiration biopsy (FNAB) specimens in order to assess FNAB's usefulness in preoperative papillary thyroid carcinoma (PTC) diagnosis with the contemporaneous analysis of RET/PTC1 and RET/PTC3 rearrangements obtained from ex vivo thyroid nodules. Design: Thyroid FNABs from 156 subjects with nodules and 49 corresponding surgical samples were examined for the presence of BRAF mutation by real-time allele-specific polymerase chain reaction, confirmed with the use of a laser pressure catapulting system. Samples were also examined for RET/PTC rearrangements. The results were compared with the cytological diagnosis and histopathology. Main outcomes: 13/156 cytological examinations were diagnostic for PTC and 19/156 showed suspicious/indeterminate FNAB (12.2\%). FNAB-BRAF ${ }^{\mathrm{V} 600 \mathrm{E}}$ mutation was detected in 11/16 (69\%) cases with histological confirmation of PTC. In our series, RET/PTC rearrangement was detected in only one case of PTC, whereas it was not present in any case of adenoma, goiter, or Hashimoto's thyroiditis. No PTC case was found positive at the same time for BRAF mutation and RET/PTC rearrangements. Conclusion: $\mathrm{BRAF}^{\mathrm{V} 600 \mathrm{E}}$ mutation detected on FNAB specimens, more than RET/PTC rearrangerangements, is highly specific for PTC and its routine research might well be an adjunctive and integrative diagnostic tool for the preoperative diagnostic iter.

\section{Introduction}

$\mathbf{T}$ HYROID CANCER HARBORS several genetic alterations, some of which have been described only in papillary thyroid carcinomas (PTCs). The classical oncogenic genetic alterations commonly seen in PTC include RET/PTC rearrangements (1-3). Among at least 10 types of RET/PTC rearrangements described, RET/PTC1, RET/PTC2, and RET/PTC3 are the most common and occur mainly in PTC and some benign adenomas, generally prevalent in pediatric populations and in patients exposed to radiation. More recently, an activating mutation in BRAF (the gene for the B-type Raf kinase, BRAF) has been described and represents the most common genetic alteration in PTC. BRAF is the most potent activator of the mitogen-activated protein kinase (MAP kinase) pathway $(4,5)$. The most frequent BRAF mutation is designated T1799A (6), resulting in a V600E (formerly designated V599E) amino acid substitution in the protein product and subsequent constitutive activation of the BRAF kinase (7-10), which accounts for the oncogenic and transforming function (7). Since their initial identification, BRAF mutations have subsequently been reported in numerous types of human cancer with various frequencies (11), such as melanomas and nevi $(7,12)$. More recently, numerous studies have consistently shown a high prevalence of BRAF mutation in thyroid cancer, ranging from 29 to $83 \%$ (13-15).

\footnotetext{
${ }^{1}$ Sezione di Endocrinologia, Dipartimento di Oncologia Sperimentale ed Applicazioni Cliniche (DOSAC), Università di Palermo, Italy.

${ }^{2}$ Sezione di Anatomia Patologica, Dipartimento di Patologia Umana, Università di Palermo, Italy.

${ }^{3}$ Divisione di Endocrinologia, Azienda Ospedaliera Villa Sofia, Palermo, Italy.

${ }^{4}$ Endocrinologia, Università di Catania, Catania, Italy.

${ }^{5}$ Sezione di Chirurgia d'Urgenza, Università degli Studi di Palermo, GENURTO, Palermo, Italy.

${ }^{6}$ Oncologia, Università degli Studi di Palermo, DDCO, Palermo, Italy.

${ }^{7}$ Chirurgia Toracica, Università degli Studi di Palermo, Chirurgia Generale, Palermo, Italy.
} 
In PTC, RET/PTC rearrangements and BRAF mutation have been commonly identified, causing tumorigenesis through the Ras $\rightarrow$ Raf $\rightarrow$ MAP kinase $(16,17)$. Fine-needle aspiration biopsy (FNAB) with cytological analysis is widely used and has become the principal tool in thyroid nodule evaluation (18). The aim of the present study was to detect BRAF mutation in cytological specimens from FNAB thyroid nodules and to assess FNAB usefulness in improving the diagnostic accuracy in the identification of PTC patients. Moreover, we evaluated RET/ PTC1 and RET/PTC3 rearrangements in ex vivo thyroid nodules for a more complete molecular analysis in PTC.

\section{Materials and Methods}

\section{Patients, high-resolution ultrasonography, and FNAB procedures}

This study was performed in accordance with the rules of the Institutional Review Board at the Faculty of Medicine, University of Palermo.

We recruited 156 subjects (36 males and 120 females; age: $49.63 \pm 14.29$ years, range: $21-83$ years) from the cohort of patients affected by thyroid nodules followed up in our outpatient clinic during September 2005 to June 2006. Because their high-resolution ultrasonography (US) features were suspicious for increased malignancy risk (hypoechoic nodules $\geq 10 \mathrm{~mm}$ with irregular margins, intranodular vascular spots, a taller-than-wider shape, or microcalcifications, grade $\mathrm{B}$ ) (19), patients underwent FNAB (US-guided FNAB) after their informed consent also for the molecular genetic analysis. Briefly, three to four aspirations with a 25- to 27-gauge needle were typically made in order to harvest material for cytological and molecular analyses. FNAB smears were stained with May Grumwald Giemsa or Papanicolau, and were considered diagnostic for PTC when they fulfilled the six diagnostic criteria required $(20,21)$. FNAB smears were considered suspicious/indeterminate when they showed only some (from three to five) of the six diagnostic features. All samples that were defined insufficient (i.e., not enough thyroid cells for diagnosis; less than six clusters of cells) underwent a further FNAB.

The schematic map of FNA-biopsied nodule/nodules was recorded and assisted the pathologist in the final identification and sampling of the thyroid nodule.

Material for molecular analysis was washed in normal saline in a $50-\mathrm{mL}$ plastic tube. After centrifugation, the pellet was resuspended and washed twice in phosphate buffer solution (PBS), and then stored at $-20^{\circ} \mathrm{C}$ until use.

\section{Histology}

After surgical resection, thyroid glands were examined by the on-call pathologist in order to identify the FNAB-treated nodule and to obtain a small tissue sample for RNA extraction (see RNA extraction from ex vivo thyroid nodules) whilst the remaining tissue was fixed in $10 \%$ neutral buffered formalin and embedded in paraffin blocks. Sections (4- $\mu$ m thick) were stained with hematoxylin-eosin for histological examination. The nuclear and architectural features were carefully evaluated for final histological diagnosis (20).

Clinicopathological data including size of tumor, extrathyroid invasion, node metastasis, associated thyroid lesions, and metastatic deposits were recorded according to the VI edition of the TNM classification (22).

\section{Detection of BRAF ${ }^{V 600 E}$ mutation}

DNA was extracted from FNAB pellets using a Qiagen DNAeasy Tissue Kit according to the manufacturer's protocol (Qiagen, Hilden, Germany). BRAF ${ }^{\mathrm{V} 600 \mathrm{E}}$ mutation was detected by real-time allele-specific amplification essentially as described by Jarry et al. (23). Amplification was performed with a Lightcycler (Roche Diagnostics GmbH, Mannheim, Germany), and fluorescence was measured within the F1 channel. After completion of the cycling process, samples were subjected to melting curve analysis. Briefly, samples were slowly cooled down $\left(0.1^{\circ} \mathrm{C} / \mathrm{s}\right)$ to $50^{\circ} \mathrm{C}$ for $30 \mathrm{~s}$ and then to a temperature ramp from $50^{\circ} \mathrm{C}$ to $90^{\circ} \mathrm{C}$ at $0.1^{\circ} \mathrm{C} / \mathrm{s}$ with continuous fluorescence monitoring. For each sample, the $-\mathrm{dF} 1 / \mathrm{dT}$ versus temperature $(\mathrm{T})$ plot was displayed, and a single narrow peak was obtained, indicating specific amplification without significant by-products. Positive results were further confirmed using a B-RAF Mutector Single-Well Test Kit (Trimgen, Tebu-Bio, Milan, Italy), following the manufacturer's instructions. Cases in which the genotype ratio (absorbance from sample/absorbance from wild type) was $\geq 2$ were interpreted as mutant (24). ARO cell DNA was used as a positive control.

\section{Laser pressure catapulting system}

In all cases histologically diagnosed as PTC, in order to avoid cell heterogeneity, which may affect the assessment of the mutational status of BRAF V600E, all resection specimens and microscopic slides were meticulously examined by two independent pathologists who were unaware of the original diagnosis and of the results of the molecular analysis (Vito Rodolico and Daniela Cabibi). Tissue sections, prepared with a microtome and placed on a slide, were processed for the laser pressure catapulting (LPC) microdissection through a Zeiss inverted microscope PALM laser Micro-Beam System (Carl Zeiss AG, Oberkochen, Germany), linked to a PC with the required software programs, as previously described (25). Genomic DNA was extracted using the QIAamp Tissue Kit (Qiagen, Hilden, Germany) with the standard protocol, and BRAF mutation detected as above described.

\section{RNA extraction from ex vivo thyroid nodules}

After surgical resection, thyroid samples from nodules obtained by means of careful identification by an experienced pathologist and corresponding to the biopsied nodule were quickly stored in RNA later (Sigma, Milan, Italy) and stored at $-20^{\circ} \mathrm{C}$ until use. Samples were further processed with the RNAEasy Mini Kit (Qiagen, Milan, Italy) for RNA extraction, following the manufacturer's instructions.

\section{Detection of RET/PTC rearrangements by $R T-P C R$}

Detection of RET/PTC1 and RET/PTC3 involved conventional two-step RT-PCR followed by agarose gel electrophoresis. Briefly, $2 \mu \mathrm{g}$ of total RNA was reverse transcribed in a volume of $20 \mu \mathrm{L}$ with random hexamer primers and Superscript II RT (Invitrogen, Milan, Italy) according to the manufacturer's protocol. Two microliters of cDNA samples was analyzed for RET/PTC1 and RET/PTC3 using 35 cycles of PCR amplification as previously reported (26). All samples were assessed for the adequacy of RNA by amplification of the beta-actin housekeeping gene and for the RET tyrosine- 
kinase domain. The PCR products were electrophoresed on a $1.5 \%$ agarose gel and visualized by ethidium bromide staining.

\section{BRAF mutation in peripheral blood lymphocytes from surgically treated patients}

Peripheral blood lymphocytes from recruited subjects were isolated by Ficoll Hypaque gradients using standard procedures, and DNA was extracted by Qiagen DNAeasy Tissue Kit according to the manufacturer's protocol.

\section{Statistical methods}

Categorical data were described as rates and proportions. The age of the patients was expressed as mean \pm standard deviation (SD). Differences in BRAF-mutated cases for histological data were calculated by Fisher test. The value of $p<0.05$ was considered statistically significant. Data were analyzed using SPSS V.13 for Windows software (Milan, Italy).

\section{Results}

\section{FNAB cytological data in relation to BRAF mutation}

One hundred and fifty-six consecutive patients with thyroid nodules underwent US-FNAB. Forty-nine patients out of 156 $(31.4 \%)$ with biopsied nodules underwent total or near-total thyroidectomy following cytological findings or for compressive symptoms, trachea dislocation, and/or esthetical reasons, differently combined for each patient.

BRAF mutation from FNAB-extracted samples was detected in 11 out of 49 (22.4\%) patients undergoing surgery. In the remaining 107 nonsurgically treated patients, we did not find any $\mathrm{BRAF}^{\mathrm{V} 600 \mathrm{E}}$ mutation. All positive samples were confirmed by a colorimetric assay. Cytological findings were conclusive for PTC in 13 and suspicious/indeterminate in 19 (12.2\%) out of 156 patients studied. With regard to BRAF mutation, FNAB cytological analyses were diagnostic for PTC in 9/11 cases, while $2 / 11$ samples were found within suspicious / indeterminate results (Table 1). Four samples were diagnostic for PTC by cytology but negative for BRAF mutation. Among 19 cases with suspicious/indeterminate FNAB, 3 cases were PTC, 1 follicular thyroid cancer (FTC), 1 Hashimoto's thyroiditis (HT), 12 goiters, and 2 adenomas, as demonstrated by histology (see Histological data in relation to BRAF mutation). Among the latter suspicious/indeterminate FNAB findings, BRAF mutation was found exclusively in two out of three PTC cases, one conventional variant $(\mathrm{CV})$ and one follicular variant (FV). In the remaining specimens involving benign thyroid diseases, no case with BRAF positivity and FNAB negativity was found, confirming the high specificity of BRAF mutation in PTC cytological specimens.

None of the 156 surgically treated or untreated patients showed a somatic mutation of BRAF in peripheral blood lymphocytes.

\section{Histological data in relation to BRAF mutation}

Among 49 patients who underwent thyroidectomy, 16 cases with PTC variants $(\mathrm{CV}=11 ; \mathrm{FV}=2$; tall-cell =3), 1 FTC, 4 adenomas (Hurthle $=1$; microfollicular $=2$; microfollicular $/$ macrofollicular $=1$ ), 26 large benign goiters, and 2 HT were histologically diagnosed (Table 1).
Table 1. Molecular Analysis of Thyroid Histology AND FNAB in 49 Patients Undergoing Thyroidectomy

\begin{tabular}{lcccc}
\hline & $\begin{array}{c}\text { BRAF } \\
\text { positivity }\end{array}$ & & $\begin{array}{c}\text { RET/PTC } \\
\text { rearrangement }\end{array}$ \\
\cline { 2 - 3 } Histology (No. of cases) & No. of cases (\%) & No. of cases (\%) \\
\hline Papillary carcinoma (16) & $11(69)$ & & 1 (6) (1 PTC3) \\
Classic variant (11) & $8(72)$ & & - \\
Follicular variant (2) & $1(50)$ & & $1(50)$ \\
Tall-cell variant (3) & $2(67)$ & & - \\
Follicular carcinoma (1) & - & - \\
Adenoma (4) & - & - \\
Microfollicular (2) & - & - \\
Micro/macrofollicular (1) & - & - \\
Hurthle (1) & - & - \\
Multinodular goiter (26) & - & - \\
Hashimoto's thyroiditis (2) & - &
\end{tabular}

Cytology (No. of cases)

No. of cases (\%) No. of cases (\%)

Diagnostic FNAB (30)

PTC (13)

Goiter (14)

Hashimoto's thyroiditis (1)

Adenoma (2)

Suspicious/indeterminate FNAB (19)

Papillary carcinoma (CV) (2)

Papillary carcinoma (FV) (1)

Follicular carcinoma (FTC) (1)

Goiter (12)

Adenoma (2)

Hashimoto's thyroiditis (1)

\begin{tabular}{|c|c|c|}
\hline Tumor stage of 16 PTC & No. of cases $(\%)$ & No. of cases $(\%)$ \\
\hline T1 (13) & $9(69)$ & $1(7.7)$ \\
\hline $\mathrm{T} 2(2)$ & 1 (50) & - \\
\hline $\mathrm{T} 4$ (1) & $1(100)$ & - \\
\hline \multicolumn{3}{|l|}{ Gender of 16 PTC } \\
\hline Male (6) & $5(83)$ & $1(16.7)$ \\
\hline Female (10) & $6(60)$ & - \\
\hline \multicolumn{3}{|l|}{ Age of 16 PTC } \\
\hline$\leq 40$ years $(12)$ & $8(67)$ & $1(8)$ \\
\hline$>40$ years $(4)$ & $3(75)$ & - \\
\hline \multicolumn{3}{|l|}{ Node metastasis (PTC) } \\
\hline Yes (3) & $2(67)$ & - \\
\hline No (13) & $9(69)$ & - \\
\hline
\end{tabular}

Data are presented as no./total no. of patients, with percentages in parentheses. FNAB: fine-needle aspiration biopsy; PTC: papillary thyroid carcinoma; CV: conventional variant; FV: follicular variant; FTC: follicular thyroid cancer.

Eleven out of 16 PTC (69\%) harbored BRAF mutation as detected in DNA extracted by both US-FNAB nodules and LPC. The highest prevalence of $\mathrm{BRAF}^{\mathrm{V} 600 \mathrm{E}}$ mutations was found in 8/11 classic PTC (72\%), whereas FV PTC had a lower prevalence (one out of two). However, it was not possible to draw statistically valid conclusions from the histological results because of the limited number of samples examined. 
We found that there was a strict concordance between BRAF mutation status and the final cytological/histological diagnosis of PTC.

$\mathrm{A}$ representative example of $\mathrm{BRAF}^{\mathrm{V} 600 \mathrm{E}}$ mutation and cytological and histological findings in one case of PTC is shown in Figure 1.

\section{$B R A F$ mutation in relation to tumor stage, gender, age, and lymph node metastases in 16 PTCs}

BRAF mutation was found in 9 out of $13 \mathrm{~T} 1$ cases (69\%), 1 out of 2 T2 cases (50\%), and 1 out of 1 T4 case (100\%) of PTC examined. As regards sex and age, BRAF mutation was detected in $5 / 6(83 \%)$ of males in comparison to $6 / 10(60 \%)$ of females as well as in $8 / 12(67 \%)$ and in $3 / 4(75 \%)$ of patients under and over 40 years, respectively. With regard to lymph node (LN) status, BRAF mutation was detected in $2 / 3$ cases with LN metastases (Table 1).
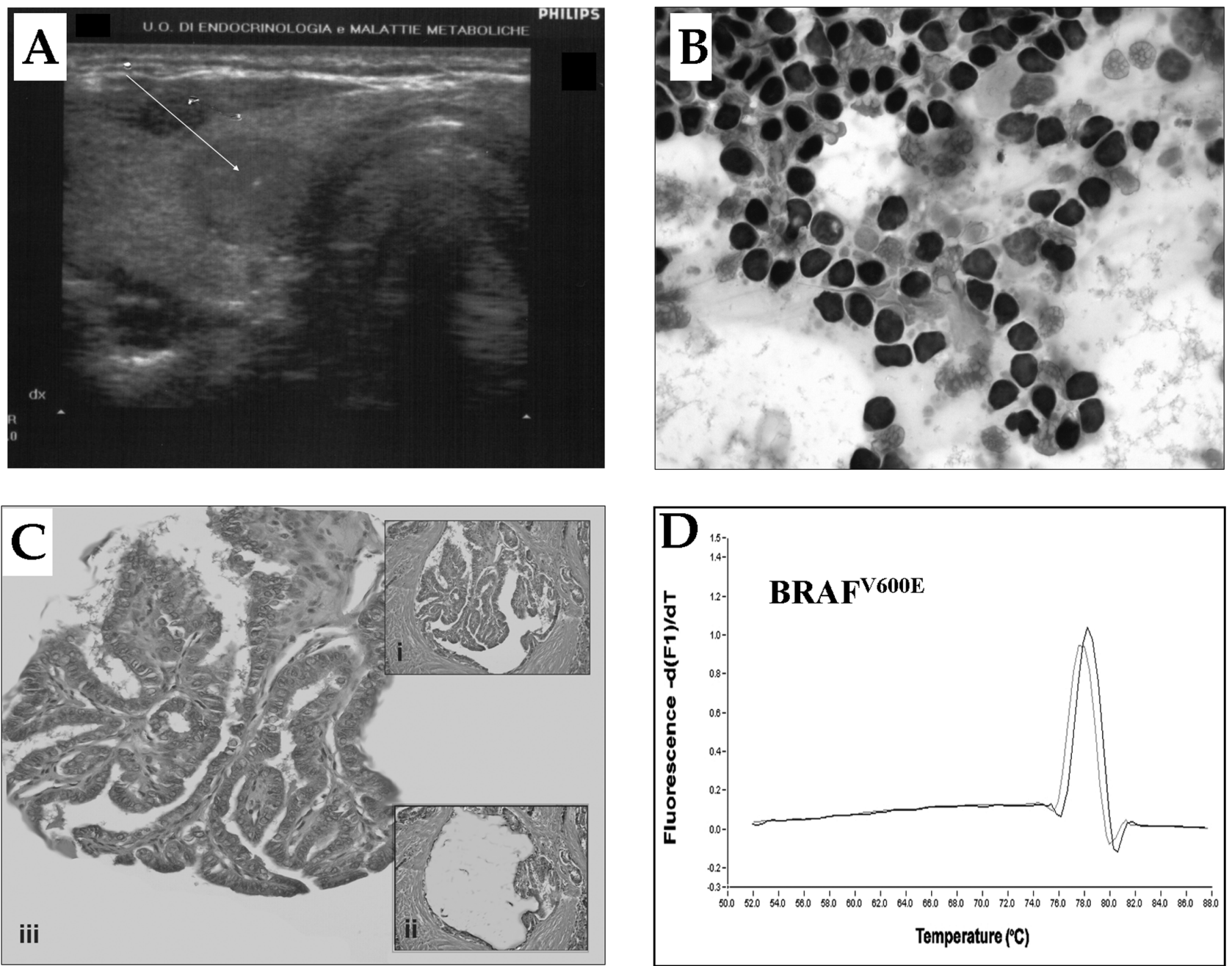

FIG. 1. (A) Representative image of fine-needle aspiration biopsy of a thyroid high-risk nodule $($ diameter $=14 \mathrm{~mm})$; $(\mathbf{B})$ cytological diagnosis of papillary thyroid carcinoma (PTC); (C) typical image of the laser pressure catapulting process involving a representative example of PTC tissue placed on a slide after the addition of $1 \mu \mathrm{L}$ of mineral oil: (i) improvement of tissue visibility after the addition of oil on the slide, (ii) cutting and catapulting of the PTC, (iii) catapulted PTC on the Eppendorf cap; (D) PTC with BRAF ${ }^{\mathrm{V} 600 \mathrm{E}}$ mutation. 
pathology shows cancer in only $20 \%$ of them (19). In this light, for patients with thyroid nodules and cytologically indeterminate findings, preoperative detection of specific molecular markers, such as the PTC-specific BRAF mutation or RET/PTC rearrangements, would be particularly helpful. Several other molecular markers for thyroid cancer have been proposed for preoperative diagnosis in FNAB such as p27, DAP4, human telelomerase reverse transcriptase, thyroid peroxidase, and galectin-3, but unfortunately reports have presented limited data because of lack of specificity or sensitivity or both (28-31). By contrast, BRAF mutation prevalence has recently been reported in $44 \%$, ranging from $28 \%$ to $83 \%$, in PTC $(18,32)$. In these studies, BRAF mutation was most common in tall-cell PTC, with an average prevalence of $77 \%$, second most common in CV PTC $(60 \%)$, and least common in FV PTC (12\%). In the present study, we demonstrate that detection of BRAF mutation on FNAB specimens can be easily and reliably performed and correctly identifies $69 \%$ of PTC, mostly expressed in conventional rather than in tall-cell variants (no significant difference was identified among the variants because of the small number of cases studied).

In our study, we used a real-time allele-specific amplification technique and a mutation detection method in order to perform a preoperative molecular analysis in a series of patients with thyroid nodules because their high-resolution US features were suspicious for increased malignancy risk. Further, we compared the tumoral BRAF mutation status detected on preoperative cytological specimens with the final histological characterization of the tumor: BRAF detection in FNAB was confirmed in their respective histological samples using both the real-time allele-specific amplification technique and the colorimetric assay.

In our study, we confirmed that BRAF gene mutation was specific for PTC $(100 \%)$, because no benign thyroid disease with nodules was found to harbor BRAF mutation. Consequently, BRAF mutation revealed the potential to be a specific molecular marker with relatively good sensitivity for the diagnosis of PTC. Other groups have detected BRAF gene mutation in both surgical and cytological samples, but the major part of this work has been conducted on retrospective studies $(13,15,23,24,32)$. The "blind" search for BRAF mutation, therefore, allowed us to identify correctly two further patients whose cytological diagnosis was not conclusive for PTC. Among 19 nodules with indeterminate/suspicious cytology, $100 \%$ of those who tested positive for BRAF mutation were PTC in comparison to only $5.3 \%$ of nodules tested negative for BRAF mutation. FNAB-BRAF mutation was, in fact, detected in 2/3 PTC cases with suspicious/indeterminate FNAB. These two cases in our study, although the small number, seem to confirm the potential usefulness of FNAB-BRAF mutation in those patients with cytologically suspicious/indeterminate thyroid nodules, according to recent literature data (33-36).

In our cohort of patients, therefore, $\mathrm{BRAF}^{\mathrm{V} 600 \mathrm{E}}$ mutation represents a diagnostic adjunctive tool even for the evaluation of thyroid nodules with indeterminate/suspicious cytological findings. The improvement in PTC diagnosis might influence the choice of treatment; that is, BRAF positivity may indicate a more appropriate extent of surgical treatment. With regard to this latter point, we strongly emphasize that in our series no patient without diagnostic or indeterminate/ suspicious FNAB was surgically treated merely because he or she was harboring BRAF mutation. However, the search for FNAB-BRAF mutation has reduced the number of indeterminate/suspicious FNAB cytology results, leading to the recovery of $66.7 \%$ of PTC.

Unfortunately, although RET/PTC rearrangement represents the other genetic lesion often present in PTC, in our study it did not lead to a more refined molecular diagnosis for PTC. Considering that the prevalence for RET/PTC rearrangerangements varies greatly according to different reports, we found that only $6 \%$ of PTC samples were RET/PTC positive, confirming its usefulness in only one case of PTC-FV (37-39).

In our series, the reason for such a limited presence of $\mathrm{RET} / \mathrm{PTC}$ is not clear. It is likely that this is due to the high presence of BRAF mutation among our PTC cases (unpublished data). On the other hand, the reduced presence of RET/PTC rearrangements might be due to the late occurrence of RET/PTC in a cell within the transformed clone. In fact, in our study we found no association of PTC with RET/ PTC and BRAF mutations. However, it remains to be ascertained whether BRAF mutations may be an alternative tumor-initiating event in PTC and whether tumors with this genotype carry a less-favorable prognosis (32-34,40-43). In our limited number of cases, we are not able to confirm this important point but we can hypothesize that the extension of these data in different PTC cohorts might address the question. At the same time, a larger long-term monitoring of disease recurrence for PTC patients with BRAF mutation might provide more definite answers regarding their prognosis.

In conclusion, our data showed that BRAF mutation, more significantly than RET/PTC rearrangements, can be readily and reliably detected on thyroid cytological specimens and has the potential to become a useful and integrative FNAB tool for the PTC diagnosis.

\section{Acknowledgment}

The authors would like to state that the present data have been offered as a contribution toward the creation and development of the Sicilian Registry of Thyroid Tumors at the Faculty of Medicine, University of Palermo, Italy. The work was partially contributed by 2005 MIUR (ex 60\%) Progetto di Ateneo to C.G.

\section{References}

1. Nikiforov YE 2002 RET/PTC rearrangement in thyroid tumors. Endocr Pathol 13:3-16.

2. Santoro M, Melillo RM, Carlomagno F, Fusco A, Vecchio G 2002 Molecular mechanisms of RET activation in human cancer. Ann N Y Acad Sci 963:116-121.

3. Tallini G 2002 Molecular pathobiology of thyroid neoplasms. Endocr Pathol 13:271-288.

4. Sithanandam G, Druck T, Cannizzaro LA, Leuzzi G, Huebner K, Rapp UR 1992 B-raf and a B-raf pseudogene are located on 7q in man. Oncogene 7:795-799.

5. Mercer KE, Pritchard CA 2003 Raf proteins and cancer: B-Raf is identified as a mutational target. Biochim Biophys Acta 1653: 25-40.

6. Kumar R, Angelini S, Czene K, Sauroja I, Hahka-Kemppinen M, Pyrhonen S, Hemminki K 2003 BRAF mutations in metastatic melanoma: a possible association with clinical outcome. Clin Cancer Res 9:3362-3368.

7. Davies H, Bignell GR, Cox C, Stephens P, Edkins S, Clegg S, Teague J, Woffendin H, Garnett MJ, Bottomley W, Davis N, Dicks E, Ewing R, Floyd Y, Gray K, Hall S, Hawes R, 
Hughes J, Kosmidou V, Menzies A, Mould C, Parker A, Stevens C, Watt S, Hooper S, Wilson R, Jayatilake H, Gusterson BA, Cooper C, Shipley J, Hargrave D, Pritchard-Jones K, Maitland N, Chenevix-Trench G, Riggins GJ, Bigner DD, Palmieri G, Cossu A, Flanagan A, Nicholson A, Ho JW, Leung SY, Yuen ST, Weber BL, Seigler HF, Darrow TL, Paterson H, Marais R, Marshall CJ, Wooster R, Stratton MR, Futreal PA 2002 Mutations of the BRAF gene in human cancer. Nature 417:949-954.

8. Dhillon AS, Kolch W 2004 Oncogenic B-Raf mutations: crystal clear at last. Cancer Cell 5:303-304.

9. Hubbard SR 2004 Oncogenic mutations in B-Raf: some losses yield gains. Cell 116:764-766.

10. Wan PT, Garnett MJ, Roe SM, Lee S, Niculescu-Duvaz D, Good VM, Jones CM, Marshall CJ, Springer CJ, Barford D, Marais R 2004 Mechanism of activation of the RAF-ERK signaling pathway by oncogenic mutations of B-RAF. Cell 116:855-867.

11. Garnett MJ, Marais R 2004 Guilty as charged: BRAF is a human oncogene. Cancer Cell 6:313-319.

12. Pollock PM, Harper UL, Hansen KS, Yudt LM, Stark M, Robbins CM, Moses TY, Hostetter G, Wagner U, Kakareka J, Salem G, Pohida T, Heenan P, Duray P, Kallioniemi O, Hayward NK, Trent JM, Meltzer PS 2003 High frequency of BRAF mutations in nevi. Nat Genet 33:19-20.

13. Namba H, Nakashima M, Hayashi T, Hayashida N, Maeda S, Rogounovitch TI, Ohtsuru A, Saenko VA, Kanematsu T, Yamashita S 2003 Clinical implication of hot spot BRAF mutation, V599E, in papillary thyroid cancers. J Clin Endocrinol Metab 88:4393-4397.

14. Kim DW, Hwang JH, Suh JM, Kim H, Song JH, Hwang ES, Hwang IY, Park KC, Chung HK, Kim JM, Park J, Hemmings BA, Shong M 2003 RET/PTC (rearranged in transformation/ papillary thyroid carcinomas) tyrosine kinase phosphorylates and activates phosphoinositide-dependent kinase 1 (PDK1): an alternative phosphatidylinositol 3-kinase-independent pathway to activate PDK1. Mol Endocrinol 17:1382-1394.

15. Xing M, Tufano RP, Tufaro AP, Basaria S, Ewertz M, Rosembaum E, Byrne PJ, Wang J, Sidransky D, Ladenson PW 2004 Detection of BRAF mutation on fine needle aspiration biopsy specimens: a new diagnostic tool for papillary thyroid cancer. J Clin Endocrinol Metab 89:2867-2872.

16. Peyssonnaux C, Eychene A 2001 The Raf/MEK/ERK pathway: new concepts of activation. Biol Cell 93:53-62.

17. Hilger RA, Scheulen ME, Strumberg D 2002 The Ras-RafMEK-ERK pathway in the treatment of cancer. Onkologie 25: 511-518.

18. Xing M 2005 BRAF mutation in thyroid cancer. Endocr Relat Cancer 12:245-262.

19. AACE/AME Task Force on Thyroid Nodule 2006 American Association of Clinical Endocrinologist and Associazione Medici Endocrinologi Medical Guidelines for the Clinical Practice for the Diagnosis and management of Thyroid Nodules. Endocr Pract 12:63-102.

20. Hedinger C, Williams ED, Sobin LH 1989 The WHO histological classification of thyroid tumors: a commentary on the second edition. Cancer 63:908-911.

21. Rosai J, Carcangiu ML, DeLellis RA 1992 Atlas of tumor pathology: tumors of the thyroid gland, 3rd series. Armed Forces Institute of Pathology, Washington, DC.

22. UICC 2002 TNM Classification of Malignant Tumours, 6th edition. John Wiley \& Sons, New York.

23. Jarry A, Masson D, Cassagnau E, Parois S, Laboisse C, Denis MG 2004 Real-time allele-specific amplification for sensitive detection of the BRAF mutation V600E. Mol Cell Probes 18: 349-352.

24. Jin L, Sebo TJ, Nakamura N, Qian X, Oliveira A, Majerus JA, Johnson MR, Lloyd RV 2006 BRAF mutation analysis in fine needle aspiration (FNAB) cytology of the thyroid. Diagn Mol Pathol 15:136-143.

25. Bazan V, La Rocca G, Corsale S, Agnese V, Macaluso M, Migliavacca M, Gregorio V, Cascio S, Sisto PS, Di Fede G, Buscemi M, Fiorentino E, Passantino R, Morello V, Tomasino RM, Russo A 2005 Laser pressure catapulting (LPC): optimization LPC-system and genotyping of colorectal carcinomas. J Cell Physiol 202:503-509.

26. Puxeddu E, Moretti S, Giannico A, Martinelli M, Marino C, Avenia N, Cristofani R, Farabi R, Reboldi G, Ribacchi R, Pontecorvi A, Santeusanio F 2003 RET/PTC activation does not influence clinical and pathological features of adult papillary thyroid carcinomas. Eur J Endocrinol 148: 505-513.

27. Segev DL, Clark DP, Zeiger MA, Umbricht C 2003 Beyond the suspicious thyroid fine needle aspirate. A review. Acta Cytol 47:709-722.

28. Troncone G, Fulciniti F, Zeppa P, Vetrani A, Caleo A, Palombini L 2000 Cyclin-dependent kinase inhibitor p27(Kip1) expression in thyroid cells obtained by fine-needle aspiration biopsy: a preliminary report. Diagn Cytopathol 23:77-81.

29. Gonzalez-Campora R, Galera-Ruiz D, Armas-Padron JR, Otal-Salaverri C, Galera-Davidson H 1998 Dipeptidyl aminopeptidase IV in the cytologic diagnosis of thyroid carcinoma. Diagn Cytopathol 19:4-8.

30. Henry JF, Denizot A, Porcelli A, Villafane M, Zoro P, Garcia S, De Micco C 1994 Thyroperoxidase immunodetection for the diagnosis of malignancy on fine-needle aspiration of thyroid nodules. World J Surg 18:529-534.

31. Giannini R, Faviana P, Cavinato T, Elisei R, Pacini F, Berti $P$, Fontanini G, Ugolini C, Camacci T, De Ieso K, Miccoli P, Pinchera A, Basolo F 2003 Galectin-3 and oncofetal-fibronectin expression in thyroid neoplasia as assessed by reverse transcription-polymerase chain reaction and immunochemistry in cytologic and pathologic specimens. Thyroid 13:765-770.

32. Xing M, Westra WH, Tufano RP, Cohen $Y$, Rosembaum E, Rhoden KJ, Carson KA, Vasko V, Larin A, Tallini G, Tolaney S, Holt EH, Hui P, Umbricht CB, Basaria S, Ewertz M, Tufaro AP, Califano JA, Ringel MD, Zeiger MA, Sidransky, Ladenson PW 2005 BRAF mutation predicts a poorer clinical prognosis for papillary thyroid cancer. J Clin Endocrinol Metab 90:6373-6379.

33. Vasko V, Hu S, Wu G, Xing JC, Larin A, Savchenko V, Trink B, Xing M 2005 High prevalence and possible de novo formation of BRAF mutation in metastasized papillary thyroid cancer in lymph nodes. J Clin Endocrinol Metab 90:5265-5269.

34. Salvatore G, Giannini R, Faviana P, Caleo A, Migliaccio I, Fagin J, Nikiforov YE, Troncone G, Palombini L, Basolo F, Santoro M 2004 Analysis of BRAF point mutation and RET/ PTC rearrangements refines the fine-needle aspiration diagnosis of papillary thyroid carcinoma. J Clin Endocrinol Metab 89:5175-5180.

35. Sapio MR, Posca D, Troncone G, Pettinato G, Palombini L, Rossi G, Fenzi GF, Vitale M 2006 Detection of BRAF mutation in thyroid papillary carcinomas by mutant allelespecific PCR amplification (MASA). Eur J Endocrinol 154: 341-348.

36. Nikiforov YE, Stewart DL, Nikiforova MN, Zhou Z, Haugen BR, Klopper JP, Fagin JA, Fidler JP, Robinson-Smith TM, Weber K 2006 Role of molecular testing for mutations in 
improving the fine needle aspiration (FNA) diagnosis of thyroid nodules. Thyroid 16:922.

37. Santoro M, Papotti M, Chiappetta G, Garcia-Rostan G, Volante M, Johnson C, Camp RL, Pentimalli F, Monaco C, Herrero A, Carcangiu ML, Fusco A, Tallini G 2002 RET activation and clinicopathologic features in poorly differentiated thyroid tumors. J Clin Endocrinol Metab 87:370-379.

38. Melillo RM, Castellone MD, Guarino V, de falco V, Cirafici AM, Salvatore G, Caiazzo F, Basolo F, Giannini R, Kruhoffer M, Orntoft T, Fusco A, Santoro M 2005 The RET/PTC-RASBRAF linear signaling cascade mediates the motile and mitogenic phenotype of thyroid cancer cells. J Clin Invest 115: $1068-1081$.

39. Zhu Z, Ciampi R, Nikirova MN, Gandhi M, Nikiforov YE 2006 Prevalence of RET/PTC rearrangements in thyroid papillary carcinomas: effects of the detection methods and genetic heterogeneity. J Clin Endocrinol Metab 91:3603-3610.

40. Shattuck TM, Westra WH, Ladenson PW, Arnold A 2005 Independent clonal origins of distinct tumor foci in multifocal papillary thyroid carcinoma. N Engl J Med 352:24062412.
41. Fagin JA 2004 Challenging dogma in thyroid cancer molecular genetics-role of RET/PTC and BRAF in tumor initiation (editorial). J Clin Endocrinol Metab 89:4264-4266.

42. Fusco A, Viglietto G, Santoro M 2005 A new mechanism of BRAF activation in human thyroid papillary carcinomas. J Clin Invest 115:20-23.

43. Ciampi R, Knauf JA, Kerler R, Gandhi M, Zhu Z, Nikirova MN, Rabes HM, Fagin JA, Nikiforov YE 2005 Oncogenic AKAP9-BRAF fusion is a novel mechanism of MAPK pathway activation in thyroid cancer. J Clin Invest 115:94-101.

Address reprint requests to: Giordano Carla, M.D. Endocrinology Section Policlinico, DOSAC Piazza delle Cliniche 2 90127 Palermo Italy

E-mail: cgiordan@unipa.it 
